\title{
CD40·FasL and CTLA-4.FasL Fusion Proteins Induce Apoptosis in Malignant Cell Lines by Dual Signaling
}

\author{
Ariel Orbach, ${ }^{*}$ Jacob Rachmilewitz, ${ }^{\dagger}$ Noam Shani, ${ }^{\ddagger}$ \\ Yonatan Isenberg, ${ }^{*}$ Miriam Parnas, ${ }^{*}$ \\ Jui-Han Huang, ${ }^{\S}$ Mark L. Tykocinski, ${ }^{\pi}$ \\ and Michal Dranitzki-Elhalel*

\begin{abstract}
From the Nephrology and Hypertension Services," and Goldyne Savad Institute of Gene Therapy, Hadassah-Hebrew University Medical Center, Jerusalem, Israel; KAHR Medical LTD, ${ }^{\ddagger}$

Jerusalem, Israel; the Department of Pathology and Laboratory Medicine, ${ }^{\S}$ University of Pennsylvania, Philadelphia, Pennsylvania; and Office of the Dean, "Tefferson Medical College, Philadelphia, Pennsylvania
\end{abstract}

Evolution of apoptosis resistance in both lymphoma and leukemia cells is well documented, and induction of apoptosis in malignant cells is a major goal of cancer therapy. Up-regulation of anti-apoptotic signals is one of the mechanisms whereby resistance to apoptosis emerges. We have previously described the fusion proteins CD40-FasL and CTLA-4·FasL, which are formed from two functional membrane proteins and induce apoptosis of activated $T$ cells. The present study explores the potential use of CD40.FasL and CTLA-4-FasL for the killing of malignant cells of lymphatic origin. Using malignant $B$ and $T$ cell lines that differ in surface expression of costimulatory molecules, we found that CTLA-4.FasL induces effective apoptosis of cells expressing CD95 and activates caspases 3, 8, and 9. Only $B 7$-expressing $B$ cells responded to CTLA-4.FasL with rapid abrogation of cFLIP expression. CD40-FasL effectively killed only the $T$ cells that express high levels of $C D 40 \mathrm{~L}$ in addition to CD95. In these cells, CD40-FasL significantly diminished cFLIP expression. Importantly, each of the fusion proteins is more potent than its respective components parts, alone or in combination. Thus, the proteins with their two functional ends deliver a pro-apoptotic signal and, in parallel, inhibit an antiapoptotic signal, thus optimizing the wanted, deathinducing effect. Therefore, these proteins emerge as promising agents to be used for targeted and specific tumor cell killing. (AmJ Pathol 2010, 177:3159-3168; DOI: 10.2353/ajpath.2010.100301)
Induction of effective and selective apoptotic death in malignant cells is a major goal for cancer therapy. The evolution of apoptotic resistance in malignant tumor cell populations is by now well documented. Apoptosis resistance can result from several mechanisms: loss of cell surface Fas receptor expression, ${ }^{1}$ interference with death complex (Death inducing signaling complex; DISC) formation, ${ }^{2}$ interference with the initiation of the caspase cascade at the DISC level, ${ }^{3}$ down-regulation of caspases downstream to the DISC, ${ }^{4}$ and up-regulation of anti-apoptotic signals at multiple levels of the death cascade..$^{5-12}$

Lymphoma and leukemia cells are resistant to apoptosis induced by chemotherapy and/or Fas ligand, presumably because of the up-regulation of anti-apoptotic or pro-surviving signals such as $\mathrm{Bcl}-\mathrm{xL}, \mathrm{Mcl}-1$, nuclear factor $\kappa \mathrm{B}(\mathrm{NF}-\kappa \mathrm{B})$, survivin, CFLIP, ${ }^{13-16}$ and even viral FLIP. ${ }^{17}$ The up-regulation of anti-apoptotic signals, which occurs normally during the activation of lymphocytes, is thought to be triggered, at least partially, by co-stimulatory signaling. When CD40 ligand (CD4OL) triggers the CD40 receptor on $\mathrm{B}$ cells, a strong survival signal is generated in both normal and malignant $B$ cells, which in turn leads to cell proliferation and enhanced survival in vitro. ${ }^{18}$ Triggering of CD40 on malignant B cells is followed by up-regulation of anti-apoptotic signals.

CD40L can be presented to malignant B cells by infiltrating $T$ cells. Interestingly, however, CD40L and CD40 are co-expressed by several types of B-cell malignancies, for example, large B-cell lymphoma. ${ }^{19}$ Therefore, an autocrine/paracrine CD40L/CD40 survival loop has been suggested as a mechanism that could explain the resistance to apoptosis of these B-cell neoplasms. ${ }^{20}$ A similar survival loop was recently proposed for cutaneous T-cell lymphoma (mycosis fungoides), where the neoplastic

\footnotetext{
Supported by KAHR Medical LTD.

Accepted for publication August 19, 2010.

N.S. is an employee of KAHR Medical LTD. A patent was issued for CD40-FasL and CTLA4-FasL and their uses.

A guest editor acted as editor-in-chief for this article. No person at Thomas Jefferson University was involved in the peer review process or final disposition for this article.

Address reprint requests to Dr. Michal Dranitzki-Elhalel, Nephrology and Hypertension Services, Hadassah-Hebrew University Medical Center, Jerusalem 91120, Israel. E-mail: michalelhalel@gmail.com.
} 
cells abnormally neo-express CD40 in addition to the CD40L that is typically expressed on T cells. ${ }^{21}$

Another molecular axis that has been implicated in autocrine/paracine-driven survival of neoplastic lymphoid cells is B7:C28. Co-stimulatory triggering of the CD28 receptor on normal $\mathrm{T}$ cells by $\mathrm{B} 7$ ligands on antigenpresenting cells is known to increase the expression of anti-apoptotic molecules. Increased costimulation via the B7:CD28 axis interferes with Fas-mediated apoptosis of T cells, and conversely, blockade of this costimulatory pathway via the therapeutic fusion protein CTLA-4・Ig increases their susceptibility to Fas-mediated apoptosis. ${ }^{22}$ There is another intriguing dimension to this ligand-receptor interaction in the context of lymphoid malignancies. CD28, while normally thought of as a receptor, can back-signal through B7 and thereby deliver a survival signal. Although this could be affected by CD28 expressed on $\mathrm{T}$ cells infiltrating the $\mathrm{B}$ cell lymphoma triggering B7-bearing malignant cells, there is also the possibility of an autocrine/paracrine survival loop in this context, given that B lymphoblastoid cells can aberrantly express CD28, in conjunction with B7 on the same cell surface. ${ }^{23,24}$ Indeed, it was shown that preventing this survival loop by applying blocking anti-CD28 antibodies (Abs) induces Fas-mediated apoptosis. ${ }^{24}$

Previously, we have described two novel fusion proteins, CTLA-4.FasL and CD40·FasL, that are members of a larger group of "signal converter proteins." 25,26 The first, paradigmatic signal converter was CTLA-4.FasL, which was designed to home to $\mathrm{B}^{+}$antigen-presenting cells (via its CTLA-4 end) and to actively send an inhibitory trans signal to activated T cells (via its FasL end). Since CTLA-4.FasL is in effect converting an activating trans signal (from an antigen-presenting cell to a $T$ cell) into an inhibitory one, it is mediating "trans signal conversion." Significantly, we have shown that CTLA-4·FasL is capable of both eliciting a pro-apoptotic Fas-driven signal and abrogating the postactivation up-regulation of an anti-apoptotic cFLIP signal. This dual mechanism of action may explain CTLA-4.FasL's potency in inducing apoptosis of activated T cells. ${ }^{27}$ CTLA-4.FasL was originally designed to act as trans signal converter (ie, to target two different molecules, B7 and Fas receptor, located on two different cells), and interfere with the trans signaling between these cells. Interestingly, however, there is the theoretical potential for CTLA-4.FasL to act in a "cis-" manner, on cells that expressB7 and Fas normally (as is the case with B cells and antigen-presenting cells), or when B7 molecules are abnormally neo-expressed on Fas-expressing cells, as is the case in a number of autoimmune and infectious disease settings. ${ }^{28,29}$

A second fusion protein, CD40.FasL, was designed to probe this concept more directly. ${ }^{26}$ CD40.FasL incorporates the combined capacities to bind to two surface receptors on activated T cells: CD40 ligand (CD40L; CD154) and Fas receptor. Hence, in principle, simultaneous triggering from both ends is possible, with the potential for "autoinhibition" if such dual triggering occurs on the same cell itself. Indeed, our data supported autoinhibition or autosuicide as the operative mechanism for
CD40.FasL in a Jurkat $T$ cell line that expresses both CD40L and Fas receptor. ${ }^{26}$

Thus, fusion proteins such as CD40·FasL CTLA-4·FasL offer a unique way to limit apoptosis induction to cells that exhibit functional binding sites for both of each protein's ends, making them selective apoptosis inducers. The present study explores the potential use of these fusion proteins for inducing apoptosis in malignant cells of lymphatic origin via intercellular or intracellular co-triggering of cognate receptors. Our findings not only establish the efficacy of these fusion proteins in driving apoptosis in neoplastic lymphoid cells, but also provide intriguing mechanistic insights into this action, with data suggesting that the pro- and anti-apoptotic signals elicited by the fusion proteins merge at the junction of FLIP/caspase 8.

\section{Materials and Methods}

\section{Cells, Abs, Reagents, and Fusion Proteins}

Daudi (CCL 213), Raji (CCL-86), and JY (77441) and HEK-293 (CRL-1573) human kidney cell lines were originally obtained from the American Type Culture Collection (Bethesda, MD). Two Jurkat sublines (J-CD40L ${ }^{+}$and $\mathrm{J}^{-C D 40 L}{ }^{-}$) were kindly provided by John Fayen (Case Western Reserve University, Cleveland, $\mathrm{OH}$ ). All cell lines were followed weekly to verify that they kept their original appearance characteristics, original growing rate, and the absence of infections. Also, cells were repeatedly tested for the expression of surface molecules. If any change was suspected, cells were not used for experiments and new ones were defrosted. Medium was tested for micoplasma by using a commercial PCR kit (Biological Industries, Beit Haemek, Israel).

Fluorescein isothiocyanate (FITC)-conjugated fluorescent Abs specific for CD40L, CD80, and CD86 were purchased from PharMingen (San Diego, CA; category numbers 555699, 305206, and 555657, accordingly), and CD95, along with their matched FITC-conjugated IgG isotypes, were purchased from eBioscience (San Diego, CA; category numbers 11-0959 and 11-4719, accordingly). Recombinant human CTLA4-Ig (CTLA-4/Fc) and sFasL were purchased from R\&D Systems (Minneapolis, MN; category number 434-CT) and Alexis Biochemicals (San Diego, CA; category number ALX-522-001), respectively. CD40-Fc fusion protein was purchased from Calbiochem (Darmstadt, Germany; category number 217588). Anti-human B7-1\&2 (CD80 and 86) were purchased from R\&D Systems (category numbers MAB 140 and MAB 141, accordingly). For Western blot analysis, anti- $\beta$ actin Abs and anti-mouse glyceraldehyde-3-phosphate dehydrogenase (GAPDH) Abs were purchased from Sigma-Aldrich, St. Louis, MO (category number A-5316) and Chemicon International, Temecula, CA (category number MAB374), respectively. AntiFLIP $_{\mathrm{S} / \mathrm{L}}$ and anti-Caspase 8 polyclonal antibodies (pAbs) were purchased from Santa Cruz Biotechnology (Santa Cruz, CA; category number sc-8347) and MBL (Medical \& Biological Laboratories Co., Nagoya, Japan; category number JM-30-20-100), respectively. Anti-Caspase 3 and 9 pAbs were purchased from Cell Signaling Technology (Danvers, MA; category numbers 9662 and 9502, accordingly). 
Culture medium for all experiments was RPMI 1640 (Biological Industries), supplemented with 10\% fetal bovine serum (Invitrogen Life Technologies, Carlsbad, CA), $2 \mathrm{mmol} / \mathrm{L}$ L-glutamine, and $100 \mathrm{U} / \mathrm{ml}$ penicillin/streptomycin (Biological Industries).

A hexahistidine-tagged derivative of CTLA-4.FasL (his ${ }_{6} \mathrm{CTLA}-4 \cdot \mathrm{FasL}$ ), with the tag appended to the amino terminus, and CD40.Fas $L$ were prepared as previously described in Huang and Tykocinski, ${ }^{25}$ Elhalel et al, ${ }^{30}$ and Dranitzki-Elhalel et al, ${ }^{26}$ respectively.

\section{Proliferation Assays}

Jurkat, Daudi, or Raji cells in exponential growth phase were washed twice and re-suspended in medium at $1 \times$ $10^{6} \mathrm{cells} / \mathrm{ml}$. Fifty microliters of cell suspension was added to individual wells of round-bottom 96-well tissue culture plates. CTLA-4-FasL, CD40-FasL, SFasL, CTLA4-Ig or CD40-Fc, or combinations of the latter three were added at different concentrations. Total culture volume was $200 \mu$ l/well. In some experiments, anti-CD80 or anti-CD86 Abs were added 20 minutes before the addition of CTLA-4.FasL. In other experiments, CTLA4.Ig in PBS was added to flat-bottom 96well plates and incubated for 1 hour at $37^{\circ} \mathrm{C}$ and then overnight at $4^{\circ} \mathrm{C}$ to precoat the plates with CTLA4.Ig. The next day, plates were washed four times with PBS, and $5 \times 10^{4}$ Raji cells were added to each well and incubated for 24 hours. Cultures were then pulsed with $0.5 \mu \mathrm{Ci}$ of $\left[{ }^{3} \mathrm{H}\right]$ thymidine (PerkinElmer, Waltham, MA; category number NET 027A001MC) and incubated at $37^{\circ} \mathrm{C}, 6 \% \mathrm{CO}_{2}$, and $95 \%$ humidity for 18 to 24 hours. Cells were subsequently harvested onto glass fiber filters for scintillation counting. All proliferation assays were performed in triplicate.

\section{Flow Cytometry}

Cells were washed twice with Fluorescence Activated Cell Sorting (FACS) buffer (0.5\% bovine serum albumin/ $0.02 \%$ sodium azide in $1 \times$ PBS) and incubated on ice for 30 to 45 minutes with one of the following: FITC-conjugated anti-CD4OL Ab; anti-CD80 Ab; anti-CD86 Abs; antiCD95 Abs; or their matching isotype controls, all purchased from PharMingen. Flow cytometry was performed by using a FACSCalibur flow cytometer (Becton Dickinson, San Jose, CA), and data were analyzed by using CellQuest software (Becton Dickinson). A total of $1 \times 10^{5}$ events were collected for each sample.

To track cells undergoing apoptosis, $1 \times 10^{6}$ Jurkat $T$ cells or $1.5 \times 10^{6}$ Raji or Daudi B cells were incubated in 24-well plates in a total volume of $1 \mathrm{ml}$, in the presence or absence of one of the following: CTLA-4·FasL; CD40.FasL; sFasL; CTLA4.Ig or CD40-Fc; or combinations of the latter three. After 4 hours (T cells) or 16 hours (B cells), cells were collected and washed twice with cold FACS buffer ( $0.5 \%$ bovine serum albumin/0.02\% sodium azide in $1 \times$ PBS). For detection of apoptosis and necrosis, cells were co-stained with propidium iodide (PI) and annexin-V-FITC by using a kit (MBL, Medical \& Biological Laboratories Co), according to the manufacturer's protocol. Flow cytometry was performed by using a FACSCalibur flow cytometer, and data were analyzed by using CellQuest software. A total of $1 \times 10^{5}$ events were collected for each sample.

\section{Whole Cell Lysates and Western Blotting Analysis}

Jurkat, Raji, JY, or Daudi cells in exponential growth phase were washed twice, re-suspended in medium at $5 \times 10^{6}$ cells $/ \mathrm{ml}$, and plated in 24-well plates in a total volume of 1 ml. CTLA-4.FasL, CD40-FasL, sFasL, CTLA4·Ig or CD40-Fc, or combinations of the latter three were added at different concentrations. After 90 to 180 minutes, cells were collected, washed twice with ice-cold PBS, and lysed in lysis buffer $(0.5 \%$ Nonidet P-40, $50 \mathrm{mmol} / \mathrm{L}$ Tris- $\mathrm{HCl}[\mathrm{pH} 8.0]$, $100 \mathrm{mmol} / \mathrm{L} \mathrm{NaCl}, 1 \mathrm{mmol} / \mathrm{L}$ phenylmethylsulfonyl fluoride, $1 \mathrm{mmol} / \mathrm{L}$ sodium orthovanadate, $10 \mu \mathrm{g} / \mathrm{ml}$ leupeptin, and $10 \mu \mathrm{g} / \mathrm{ml}$ aprotinin) for 20 to 30 minutes on ice. The protein concentration of whole cell lysates was determined by using the Bio-Rad Protein Assay Kit (BioRad, Richmond, CA), according to the manufacturer's protocol. Whole cell lysates were mixed with Laemmli sample buffer (Bio-Rad) at 1:1 ratio, heated for 10 minutes at $95^{\circ} \mathrm{C}$, and equal amounts of protein were loaded onto $10 \%$ SDS-polyacrylamide gel electrophoresis (PAGE). Following electrophoresis, gels were blotted onto nitrocellulose membranes (Schleicher \& Schuell, Dassel, Germany), blocked with $5 \%$ milk/PBS, and probed overnight with primary Abs. After extensive washing, blots were incubated with horseradish peroxidase-conjugated matching secondary Abs (Bio-Rad), and developed with enhanced chemiluminescent substrate (Sigma-Aldrich) before exposure to X-ray film. Films were scanned and quantified by ImageMaster VDS-CL (Amersham Pharmacia Biotech, Piscataway, NJ). All membranes were re-blotted with either anti- $\beta$ actin monoclonal $\mathrm{Ab}(\mathrm{mAb})$ or anti-GAPDH mAb to verify that similar quantities of protein were loaded on the gel.

\section{Statistical Analyses}

All results are expressed as mean \pm SD. Data were analyzed by analysis of variance to compare between the different experimental groups. $P<0.05$ was considered statistically significant.

\section{Results}

\section{Fusion Protein-Mediated Inhibition of Cell Proliferation Is Dependent on the Surface Expression of Cognate Receptors}

As a first step, we established the functionality of the component domains of the CTLA-4.FasL and CD40.FasL fusion proteins. To this end, we used malignant B (Raji, JY, and Daudi) and T (Jurkat) cell lines that differ in the expression of counterreceptors for these fusion protein elements-namely B7 (CD80 and CD86), CD40 ligand (CD40L), and Fas receptor (CD95). In the case of Jurkat, two sublines that differ in their expression of CD40L ( $\mathrm{J}$ $\mathrm{CD}_{40 \mathrm{~L}^{+}}$versus $\left.\mathrm{J}_{-} \mathrm{CD}_{40 \mathrm{O}}{ }^{-}\right)^{26}$ were paired. To start, we 


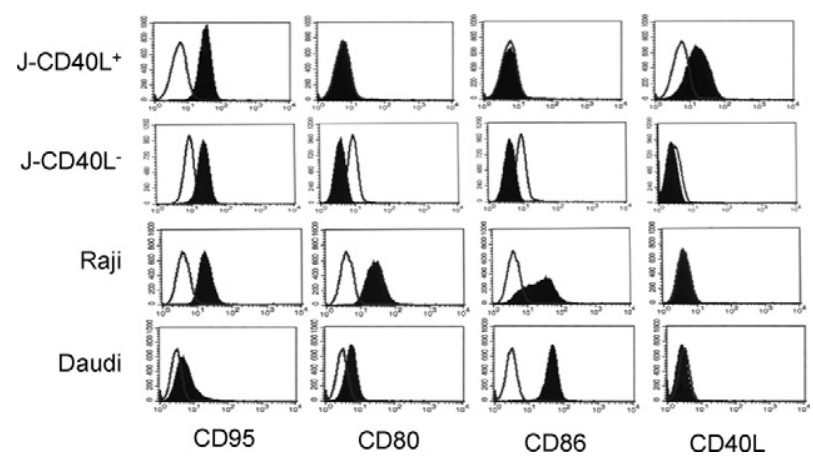

Figure 1. The expression of cell surface receptors on $\mathrm{T}$ and $\mathrm{B}$ malignant cells. CD40L-expressing (J-CD40L ${ }^{+}$) and -nonexpressing $\left(\mathrm{J}-\mathrm{CD} 40 \mathrm{~L}^{-}\right.$) malignant $\mathrm{T}$ cell line, and Raji and Daudi malignant $\mathrm{B}$ cell lines were immuno-stained with FITC-conjugated anti-CD95, anti-CD80, anti-CD86, or anti-CD40L mAb (in black) or with Isotype control (white) and analyzed by flow cytometry.

verified surface expression of the molecules on these various cell lines by immunofluorescence and flow cytometry (Figure 1). As expected, the B and T cell lines were positive and negative for B7 molecules, respectively, and Daudi cells expressed negligible levels of Fas receptor. We also confirmed the difference in CD40L expression between the $\mathrm{J}_{-\mathrm{CD} 40 \mathrm{~L}^{+}}$and $\mathrm{J}_{-\mathrm{CD} 40 \mathrm{~L}^{-}} \mathrm{T}$ cell sublines.

Next, we determined whether the differences in cognate surface receptor expression correlate with the abilities of CTLA-4.FasL and CD40.FasL to inhibit the proliferation of the tumor lines (Figure 2A). Specifically, the different cell lines were pulsed with $\left[{ }^{3} \mathrm{H}\right]$ thymidine for 16 to 20 hours in the presence or absence of CTLA-4.FasL, CD40.FasL, CTLA4•Ig, CD40-Fc, sFasL, or different combinations of the latter three. As expected, the proliferation of Daudi cells, which express minimal Fas receptor, was not inhibited by either of the FasL-containing fusion proteins, CTLA-4·FasL and CD40·FasL, nor by sFasL (Figure $2 \mathrm{~A}$, lowest panel), highlighting the Fas-dependence of their inhibitory activity. In contrast, these fusion proteins significantly inhibited proliferation of the other two malignant B cell lines, Raji (Figure 2A) and JY (not shown), which do express the Fas death receptor. CTLA-4.FasL was substantially more potent than sFasL and CTLA4.Ig, alone or in combination, in inhibiting proliferation of the B7-expressing malignant B cells. Indeed, CTLA4・Ig had no effect on proliferation at concentrations as high as 100 $\mathrm{ng} / \mathrm{ml}$. Of note, CTLA-4·FasL was significantly more effective than CD40.FasL against the B cell lines (which are negative for CD40L). In fact, CD40·FasL, at concentrations up to $30 \mathrm{ng} / \mathrm{ml}$, had no inhibitory effect on the B cell lines.

To further explore the requirement for CD40L expression on target cells for CD40.FasL's activity, we took advantage of the Jurkat $T$ cell derivative lines that differ in CD40L expression ( $\mathrm{J}-\mathrm{CD} 40 \mathrm{~L}^{+}$versus $\mathrm{J}_{-} \mathrm{CD} 40 \mathrm{~L}^{-}$). Both of these $T$ cell lines were inhibited by sFasL and FasLcontaining fusion proteins to a greater extent than Raji $B$ cells (Figure 2A, upper two panels), with the $\mathrm{J}^{-C D 40 L^{-}}$line being the most sensitive. Interestingly, as we have shown previously, ${ }^{26}$ only cells that express CD40L (J-CD40L ${ }^{+}$) were affected by low concentrations of CD40.FasL, though at higher concentrations of CD40·FasL (eg, $\geq 100 \mathrm{ng} / \mathrm{ml}$ ), all Fas-expressing cells were inhibited to some degree (not shown).

Given that $\mathrm{T}$ cells were highly sensitive to all forms of sFasL, we could not use them as B7-negative controls for establishing the requirement for $\mathrm{B} 7$ surface expression in CTLA-4.FasL's activity. Consequently, we performed an Abs blocking experiment by using B7-positive B cells as

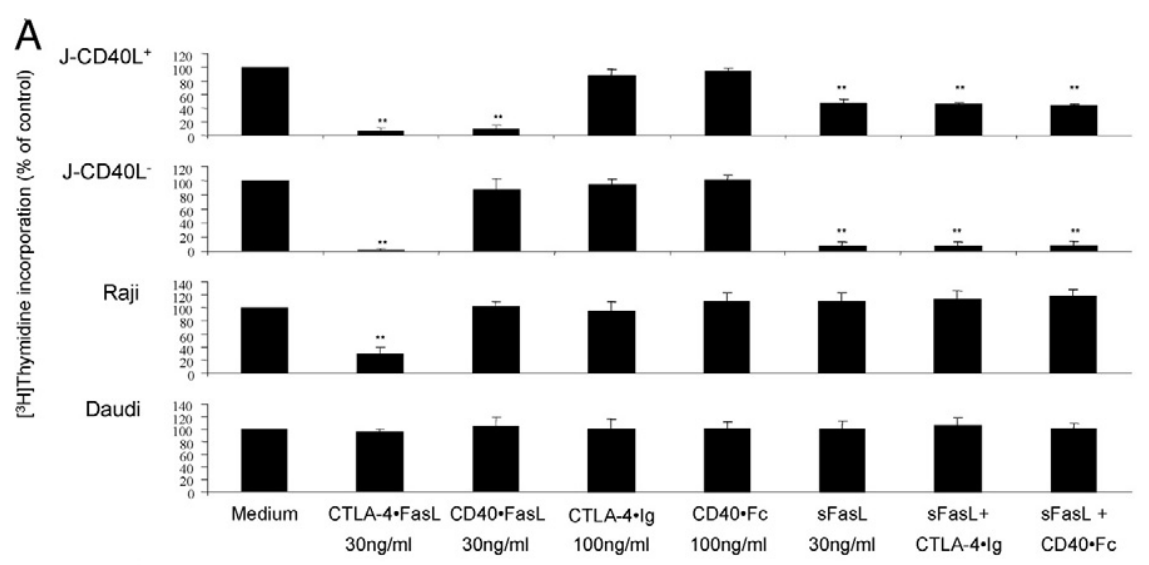

B $\square$ None

- CTLA-4.FasL $30 \mathrm{ng} / \mathrm{m}$

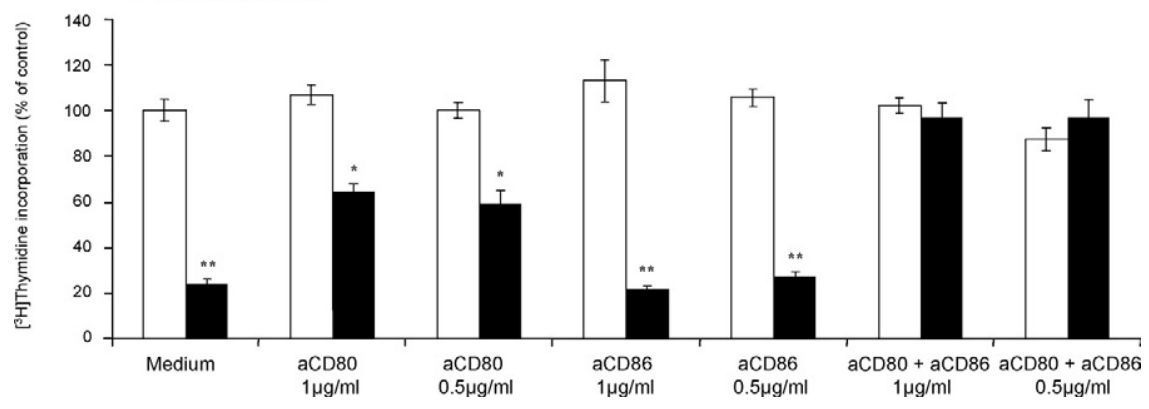

Figure 2. Target cell susceptibility to $\mathrm{J}_{-\mathrm{CD}} 40 \mathrm{~L}^{+}$ and $\mathrm{J}-\mathrm{CD} 40 \mathrm{~L}^{-}$is dependent on relevant receptor expression. A: CD40L-expressing (J-CD40L ${ }^{+}$) and -nonexpressing $\left(\mathrm{J}-\mathrm{CD} 40 \mathrm{~L}^{-}\right)$malignant $\mathrm{T}$ cells (upper two panels) and Raji and Daudi malignant B cells (lower two panels) were plated $\left(0.5 \times 10^{5}\right)$ in round-bottom, 96-well plates in the presence or absence of CTLA$4 \cdot$ FasL, CD $40 \cdot$ FasL (30 ng/ml each), sFasL (30 $\mathrm{ng} / \mathrm{ml})$, CTLA- $4 \cdot \mathrm{Ig}(100 \mathrm{ng} / \mathrm{ml})$, and CD40-FC $(100 \mathrm{ng} / \mathrm{ml})$ or their combination as indicated, pulsed with $\left[{ }^{3} \mathrm{H}\right]$ thymidine, and incubated for 18 hours. Assays were performed in triplicates. Data are presented as percentage of $\left[{ }^{3} \mathrm{H}\right]$ thymidine incorporation of cells in incubated in growth medium. These results summarize three independent experiments for each cell line. ${ }^{*} P<0.05$ versus control; ${ }^{* *} P<0.01$ versus control. B: $0.5 \times 10^{5}$ Raji cells were incubated with (black bars) or without (white bars) CTLA$4 \cdot$ FasL $(30 \mathrm{ng} / \mathrm{ml})$ in the presence of either antiCD80 or anti-CD86 (B7 blockers) or their combination for 18 hours. Proliferation was estimated and presented as in $\mathbf{A}$. These results summarize three independent experiments ${ }^{*} P<0.05$ versus control $P<0.05$; *** $P<0.01$ versus medium. 


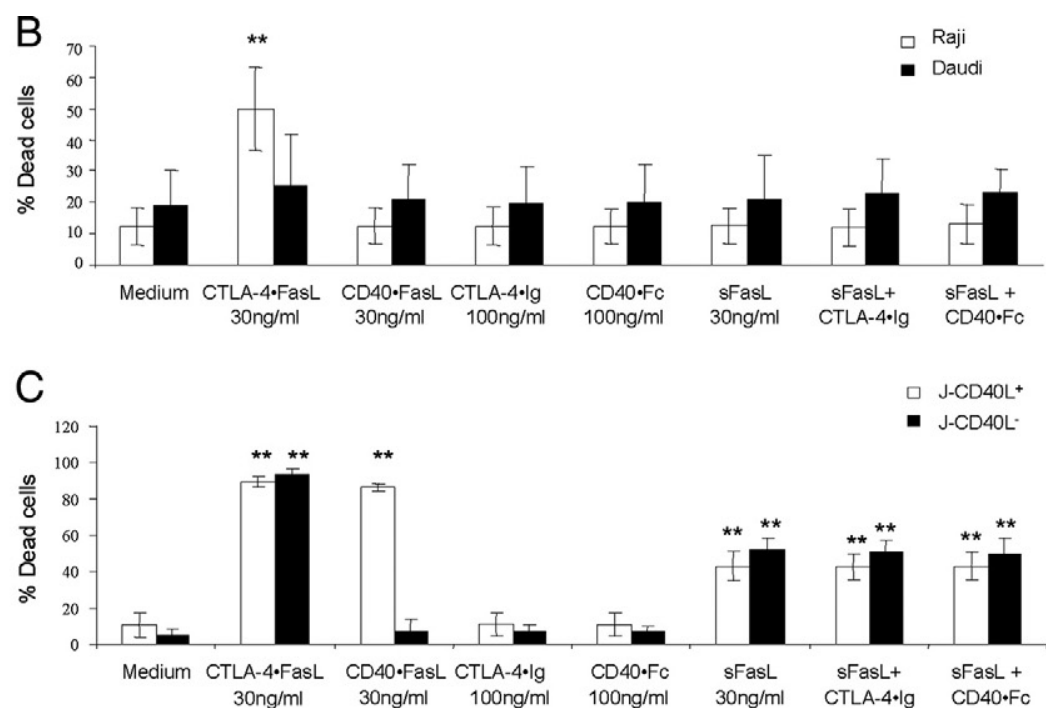

Figure 3. Target cell susceptibility to apoptosis induction by $\mathrm{J}-\mathrm{CD} 40 \mathrm{~L}^{+}$and $\mathrm{J}_{-} \mathrm{CD} 40 \mathrm{~L}^{-}$is dependent on relevant receptor expression. $\mathrm{J}_{-\mathrm{CD}} 40 \mathrm{~L}^{+}$, $\mathrm{CD} 40 \mathrm{~L}$ (J-CD40L ${ }^{-}$), and Raji and Daudi cells were incubated in the presence or absence of either CTLA- $4 \cdot \mathrm{FasL}(30 \mathrm{ng} / \mathrm{ml}), \mathrm{CD} 40 \cdot \mathrm{FasL}(30 \mathrm{ng} / \mathrm{ml}), \mathrm{sFasL}(30 \mathrm{ng} / \mathrm{ml})$, CTLA-4.Ig $(100 \mathrm{ng} / \mathrm{ml})$, CD $40-\mathrm{Fc}(100 \mathrm{ng} / \mathrm{ml})$, or their combination as indicated for 4 ( $\mathrm{T}$ cells) or 16 hours (B cells). Cells were harvested and costained with AnnexinV and PI. FACS analysis was performed. A: A representative dot plot analysis of the cell lines in the presence or in the absence of CTLA- $4 \cdot$ FasL or CD40·FasL. B and C: Percentage of dead cells (Annexin $\mathrm{V}^{+} / \mathrm{PI}^{-}+$Annexin $\mathrm{V}^{+} / \mathrm{PI}^{+}$) obtained from FACS analysis of Raji and Daudi malignant B cell lines (B), Jurkat malignant $\mathrm{T}$ cell lines $(\mathbf{C})$. The summary of three independent experiments is shown. Data are presented as mean $\pm \mathrm{SD}$. ${ }^{* *} P<0.01$ versus medium.

targets. In particular, we compared CTLA-4·FasL-mediated inhibitory effect in the absence or presence of antagonistic Abs against CD80 and CD86 (Figure 2B). Anti-CD80 blocking $\mathrm{Abs}(0.5$ or $1 \mu \mathrm{g} / \mathrm{ml})$ significantly attenuated the inhibitory effect of CTLA-4.FasL (30 ng/ml). In contrast, antiCD86 Abs, at the same concentrations, had no effect on CTLA-4.FasL inhibition of Raji cell proliferation. The addition of the two blocking Abs in combination completely abolished CTLA-4·FasL's inhibitory effect. Adding nonrelevant Abs resulted in no effect. Taken together, these data indicate that CTLA-4·FasL and CD40·FasL exhibit maximal inhibitory potency when the target malignant lymphoid lines express cognate counterreceptors for both domains of each fusion protein.

\section{Fusion Protein-Mediated Induction of Apoptosis Is Dependent on the Surface Expression of Cognate Receptors}

Our previous studies have established that both CTLA4.FasL and CD40.FasL induce their inhibitory effect via Fas-mediated apoptosis. This was established previously by using either blocking Ab directed against Fas receptor or splenocytes taken from $\mathrm{Ipr}^{-1-}$ mice. ${ }^{30,31}$ We next asked whether apoptosis induction by these fusion proteins parallels proliferative inhibition in being more efficient when target cells express surface molecules that can bind both ends of the respective proteins. To this end, the same set of malignant cell lines were incubated for 4 ( $T$ cells) or 16 (B cells) hours in the presence or absence of CTLA-4.FasL, CD40-FasL, CTLA4-Ig, CD40-Fc, sFasL, or different combinations of latter three. At the end of the treatment period, cellular apoptosis and necrosis were assessed using Annexine/PI staining and flow cytometry. Again as expected, FasL-containing fusion proteins or sFasL had no effect on Daudi B cells lacking Fas receptor, and neither CTLA-4.Ig or CD40-FC induced apoptosis in the Daudi cells (Figure 3, A and B). By contrast, and as was the case in the proliferation assay, CTLA-4.FasL significantly increased the percentage of apoptotic or necrotic cells at 16 hours (Figure 3, A and B). Again, more apoptosis was detected when Raji cells were incubated with CTLA-4.FasL, as opposed to sFasL, CTLA-4-Ig, or a combination of the latter two. No significant apoptosis of Raji cells was induced by CD40. FasL (Figure 3, A and B).

When Jurkat T cells (either J-CD40L ${ }^{+}$or J-CD40L ${ }^{-}$) were incubated for 4 hours with CTLA-4.FasL, significant apoptosis ensued (Figure 3, A and C), though when tested by proliferation assays (Figure 2A), J-CD40L ${ }^{+}$were less affected than $\mathrm{J}_{-C D} 40 \mathrm{~L}^{-}$by CTLA-4.FasL than $\mathrm{J}^{-C D 40 \mathrm{~L}^{-}}$. This is probably due to the fact that the AnnexinV staining detects early stages of apoptosis. However, when the Jurkat cell lines were incubated in the presence of CD40.FasL, significant apoptosis could be detected only in $\mathrm{J}^{-C D 40 L^{+}}$ cells, despite the fact that CTLA-4.FasL and sFasL were more potent in inducing cell death in $\mathrm{J}^{-C D 40 L}{ }^{-}$cells (Figure $2 \mathrm{~A}$ ). This set of experiments highlighted the functional importance of both ends of each of the respective fusion proteins for efficient apoptosis induction.

\section{Both Pro-Apoptotic and Anti-Apoptotic Pathways Are Affected by CTLA-4·FasL and CD40.FasL}

We next considered the possibility that the apoptosisinducing activity of CTLA-4.FasL and CD40-Fas may not be solely reliant of Fas death receptor triggering. This was prompted by our previous demonstration that CTLA4.FasL interferes with the up-regulation of the anti-apoptotic protein CFLIP in T cells undergoing activation. ${ }^{27}$ To 

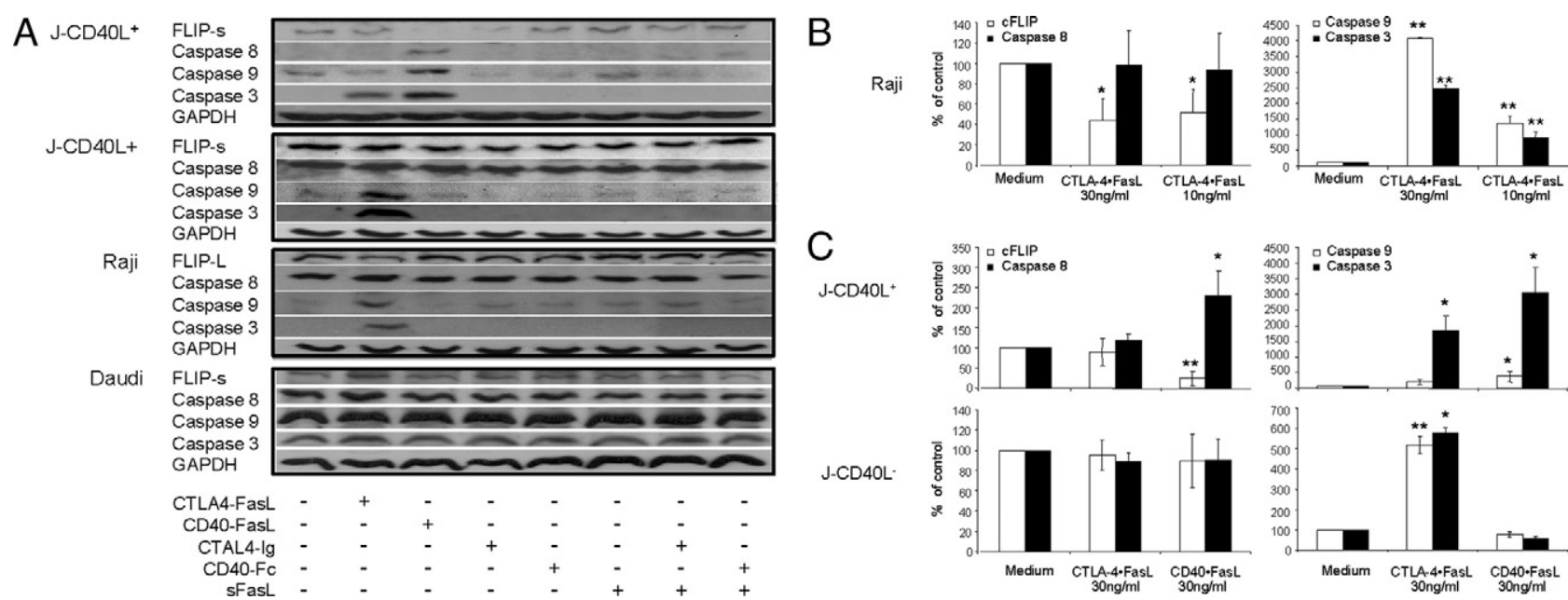

Figure 4. CD 40.FasL and CTLA4·FasL effects on the expression of apoptotic and anti-apoptotic signaling. $\mathrm{J}^{-\mathrm{CD} 40 \mathrm{~L}^{+}}$, J-CD40L ${ }^{-}$, and Raji and Daudi cells were incubated in the presence or absence of either CTLA-4·FasL, CD 40•FasL, sFasL, CTLA-4•Ig, CD40-Fc, or their combinations as indicated for 90 minutes. Cells were collected, and whole cell lysates were fractionated on 10\% SDS-PAGE and immunoblotted with the indicated Abs. A: Representative immunoblots for Jurkat malignant T cell lines and Raji and Daudi malignant B cell lines. This is a representative experiment of at least three independent experiments for each cell line. $\mathbf{B}$ and $\mathbf{C}$ : Summary of three independent experiments with the indicated Abs for Raji (B) and Jurkat (C) cell lines. The active forms of caspases 3, 9, and 8 are shown. Data were normalized against GAPDH. Expression of proteins in cells incubated in medium (control) were considered as $100 \%$. Data are presented as mean $\pm \mathrm{SD} .{ }^{*} P<0.05$ versus medium; ${ }^{* *} P<0.01$ versus medium

test this hypothesis, the T and B cell lines were incubated for 90 to 180 minutes with CTLA-4·FasL, CD40·FasL, sFasL, CTLA4-Ig, CD40, or combinations of the latter three. At the end of the incubation period, whole cell lysates were evaluated by immunoblotting for expression of the anti-apoptotic protein CFLIP, casapse 8 (as a marker of the extrinsic pathway), caspase 9 (as a marker of the intrinsic, mitochondrial pathway), and caspase 3. Of note, we looked for both the pro-caspase forms (not shown) and the cleaved, active caspase forms. A representative experiment is shown in Figure 4A, and the summary of three independent experiments performed with the different cell lines is shown in Figure 4, A-C. The expression of the different caspases in Daudi B cell line (with negligible Fas receptor) did not change after incubation with the FasL-containing proteins (Figure 4A). Furthermore, no change was found when Daudi cells were incubated with CTLA4-Ig, CD40-Fc, or a combination of the latter with sFasL (Figure 4A). In contrast, B cell lines co-expressing B7 molecules and Fas receptors yielded an entirely different picture. After 90 or 180 minutes of incubation in the presence of CTLA-4.FasL, the CFLIP expression was abrogated, and a clear increase in the activated (cleaved) forms of two of the caspases ( 9 and 3 ) was seen. Since caspase 8 is found mainly in its active, cleaved form in these cells, even when Fas receptor is not triggered and cFLIP base levels are very low, we chose to look at another malignant B cells line, JY, also co-expressing B7 molecules and Fas receptor (Figure 5A). When incubated with CTLA-4.FasL, there was a clear decrease in cFLIPs abundance and a significant increase in the activated forms of caspases 3, 9, and 8 (Figures 5, B-D). In contrast, CD40.FasL, sFasL, CTLA4-Ig, or CD40-Fc had no effect on cFLIP expression or caspase activation in either of the malignant B cell lines (Figures 4 and 5).

We next focused on CD40.FasL with an appropriate cell target, $\mathrm{J}_{-\mathrm{CD} 40 \mathrm{~L}}{ }^{+}$. When the $\mathrm{J}_{-\mathrm{CD} 40 \mathrm{~L}}{ }^{+}$and
$\mathrm{J}^{-C D 40 L^{-}}$T cell lines were incubated with CTLA-4·FasL or CD40.FasL, the pattern expression of apoptotic and anti-apoptotic protein expression was distinctly different from that seen with the B cell lines (Figure 4A, upper two panels; Figure 4C). In both Fas-expressing Jurkat cell lines, CTLA-4.FasL and CD40.FasL each activated the caspase cascade, showing increased abundance of the activated forms of caspase 9 and 3. Caspase 8 appears in its activated form in these cell lines. No change in cFLIPs abundance was noted. However, J-CD40L ${ }^{+}$cells, though less sensitive to CTLA-4.FasL than $\mathrm{J}^{-C D 40 L}{ }^{-}$(as one reflected in the lesser increase in the activated forms of caspase 9 and 3), responded to CD40.FasL treatment with a significant decrease in cFLIPs abundance and additional activation of caspases 8, 3, and 9. CD40.FasL was more potent in doing so than CD40-Fc, sFasL, or a combination of the two. Taken together, these experiments establish that CTLA-4·FasL and CD40·FasL each has dual and reinforcing affects on both apoptotic (caspase) and antiapoptotic (cFLIP) pathways.

\section{CTLA4-Ig Inhibits Proliferation of a B Cell Line and Decreases cFLIP Levels}

One possible explanation for the special properties of the fusion proteins, with unique impact on anti-apoptotic signaling, is back-signaling through the non-Fas surface counterreceptors. Indeed back-signaling through the "costimulatory ligands" B7 (on antigen-presenting cells) and CD40L (on T cells) has been documented by others. ${ }^{32-35}$ We therefore asked whether the exceptional potency of the CTLA-4.FasL and CD40.FasL fusion proteins might be explained, at least in part, by back-signaling through B7 and CD40L, respectively, occurring simultaneously with Fas receptor triggering. For that purpose, Raji B cells were treated with CTLA-4·FasL for 24 hours, in 
A

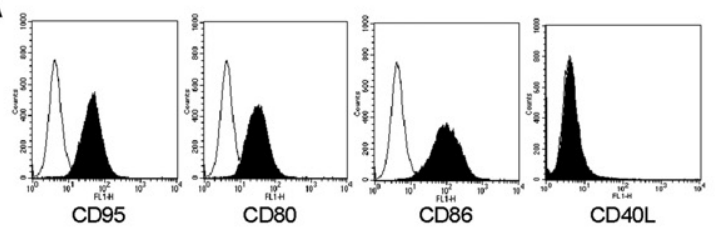

B

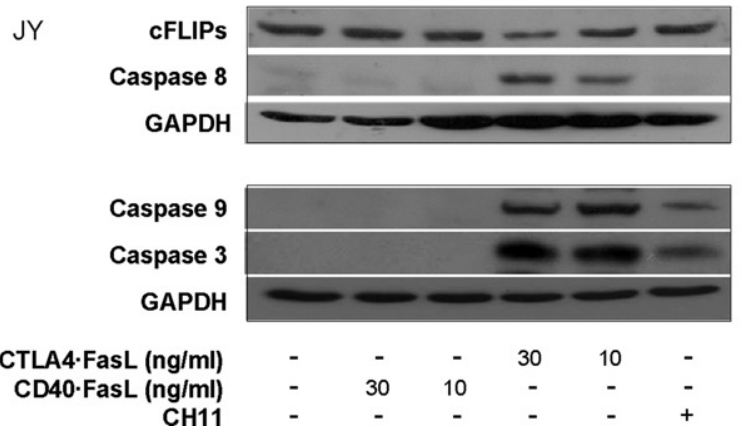

C

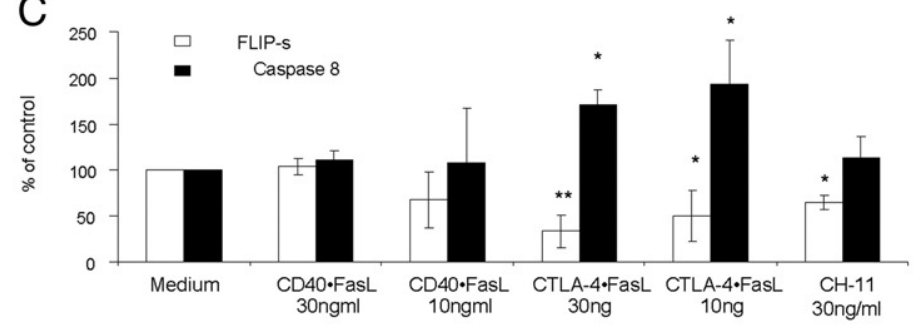

D

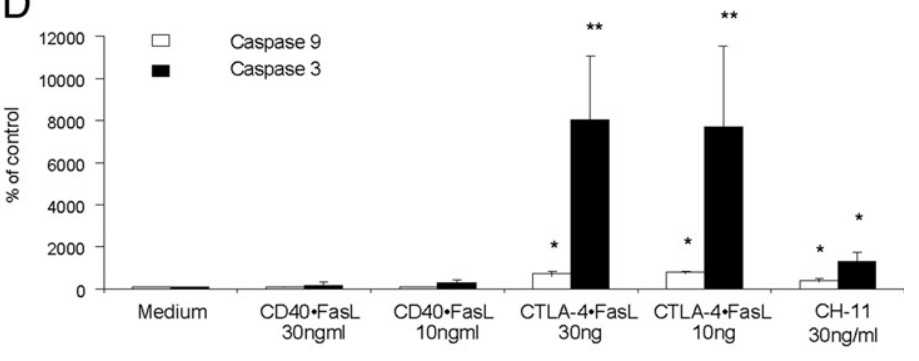

Figure 5. CTLA4-FasL increases apoptotic signals and decreases the anti-apoptotic protein cFLIP in JY malignant B cells. JY cells were incubated in the presence or absence of either CTLA-4.FasL, CD 40-FasL, or anti-Fas Abs (CH11), for 90 minutes. Cells were collected, and whole cell lysates were fractionated on $10 \%$ SDS-PAGE and immunoblotted with the indicated Abs. A: JY cells were immuno-stained with FITC-conjugated anti-CD95, anti-CD80, anti-CD86, or anti-CD40L $\mathrm{mAb}$ (in black) or with Isotype control (white) and analyzed by flow cytometry. B: Representative immunoblots of three independent experiments for each cell line. C: Summary of three independent experiments of JY malignant B cell lines with cFLIPs and anti-caspase 8 Abs. D: Summary of three independent experiments of JY malignant B cell lines with anti-caspase 9 and 3 Abs. Expressions of proteins in cells incubated in medium (control) were considered as 100\%. Data are presented as mean $\pm \mathrm{SD} .{ }^{*} P<0.05$ versus medium; ${ }^{* *} P<0.01$ versus medium.

the presence or absence of plate-bound CTLA4-Ig, and proliferation was assessed. As shown in Figure 6A, platebound CTLA4-Ig alone significantly inhibited Raji cell proliferation. CTLA-4·FasL-mediated inhibition of Raji cell proliferation was diminished in the presence of platebound CTLA4-Ig, suggesting interference with CTLA$4 \cdot F a s L$ binding to B7 (Figure 6B). Significantly, platebound CTLA4-Ig, and as was the case for CTLA-4.FasL, reduced cFLIP expression in the Raji cells and increased the expression of caspases 9 and 3 in them (Figure 6C). These findings suggest that CTLA4-Ig can deliver an inhibitory back-signal to malignant $B$ cells and reduce anti-apoptotic cFLIP in them.

We also asked whether CD40·FasL can mediate analogous back-signaling through CD40L. To test this possibility, we incubated $\mathrm{J}_{-\mathrm{CD} 40 \mathrm{~L}^{+}}$cells with CD40-Fc. CD40-Fc increased $\mathrm{J}_{-\mathrm{CD} 40 \mathrm{~L}^{+}}$proliferation in $\sim 20 \%$ (not shown). However, no effect on the expression of the apoptotic and antiapoptotic proteins was observed when CD40-Fc was used at concentrations up to $1200 \mathrm{ng} / \mathrm{ml}$ (data not shown).

\section{Discussion}

In this study, we have explored the unique properties of two trans signal converter proteins, CTLA-4·FasL and CD40.FasL, as inducers of apoptosis of malignant lymphoid cell lines, focusing on relevant intracellular signaling cascades. The main findings were (1) CTLA-4.FasL and CD40.FasL induce death in Fas receptor-expressing
A

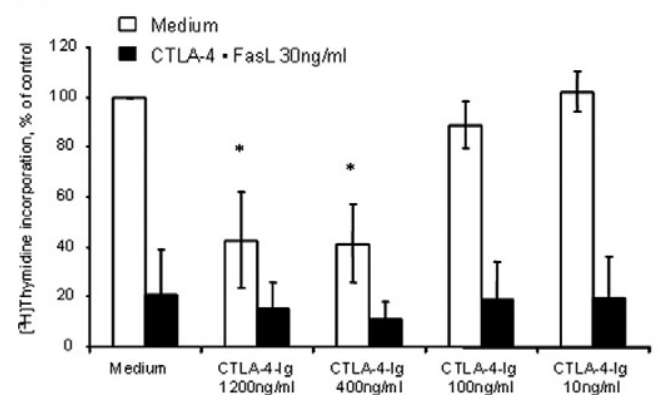

B

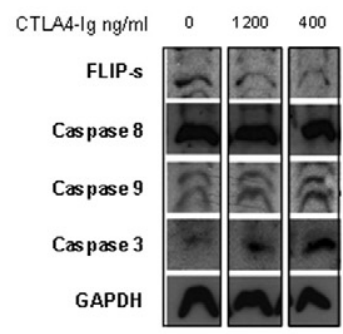

C

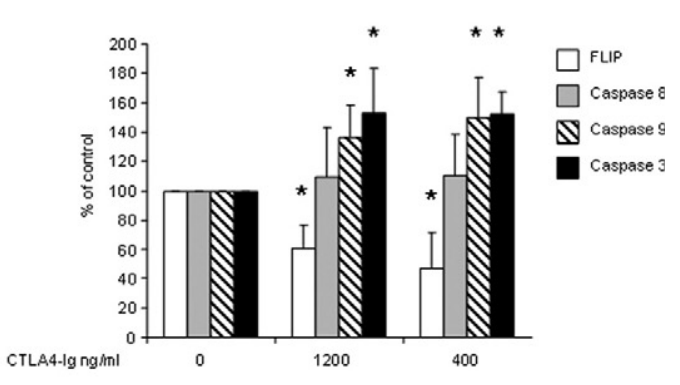

Figure 6. CTLA-4-Ig reduces B7 expressing cells proliferation and affects Caspases and cFLIP expression. A: Raji malignant B cells were incubated in the presence or absence of CTLA- $4 \cdot$ FasL on a flat-bottom, 96-well plate that was pre-incubated with CTLA-4-Ig overnight. Assays were performed in triplicate. Cells were pulsed with $\left[{ }^{3} \mathrm{H}\right]$ thymidine, incubated for 24 hours, and then evaluated for $\left[{ }^{3} \mathrm{H}\right]$ thymidine incorporation. $\left[{ }^{3} \mathrm{H}\right]$ thymidine incorporation of cells in medium (control) was designated as $100 \%$, and the rest are presented as percent of control, mean \pm SD. ${ }^{*} P<0.05$ versus control; ${ }^{* *} P<0.01$ versus control. This is a summary of three independent experiments. B and C: Raji cells were incubated on 24-well plate bound to CTLA-4-Ig for 90 minutes. Cells were collected, and whole cell lysates were fractionated on 10\% SDS-PAGE and immunoblotted with the indicated Abs. B: Representative immunoblots with the indicated Abs. C: Summary of three independent experiments. The active forms of caspases 3, 9, and 8 are shown. Data were normalized against GAPDH. Expression levels of proteins in cells incubated in medium (control) were considered as $100 \%$. Data are presented as mean \pm SD. ${ }^{*} P<0.05$ versus medium. 
malignant lymphoid lines of both B and T lineage; (2) CTLA4.FasL induces apoptosis in B7-expressing B cell lines more potently than CD40.FasL; (3) CD40.FasL induces apoptosis in CD4OL-expressing $\mathrm{J}_{-} \mathrm{CD}_{40 \mathrm{~L}}{ }^{+}$cells in a CD40Ldependent fashion; (4) CTLA-4·FasL lowers cFLIP expression and activates the caspase cascade in cells bearing both B7 and Fas receptor; (5) CD40-FasL lowers cFLIP expression and activates the caspase cascade in cells bearing both CD40L and Fas receptor; and (6) CTLA4.FasL and CD40.FasL are each more effective in inducing apoptosis than either of their components, alone or in combination. Taken together these findings affirm the higher order functionality of these unique fusion proteins, and suggest that they may have special advantages for inducing apoptosis in malignant lymphoid cells, by coordinately affecting apoptotic and anti-apoptotic pathways in such cells.

One of the mechanisms enabling malignant cells to escape apoptosis, and thereby remain refractory to treatment, is up-regulation of anti-apoptotic proteins. ${ }^{5-12}$ FLIP, expressed either intrinsically (as cFLIP) or extrinsically (as viral FLIP), ${ }^{17,36}$ has been implicated as a key anti-apoptotic protein in several malignant lymphomas. We have previously shown that CTLA-4.FasL prevents the up-regulation of cFLIP expression that normally accompanies T cell activation. ${ }^{27}$ By abrogating up-regulation of this anti-apoptotic protein, CTLA-4.FasL is able to induce apoptosis in activated $\mathrm{T}$ cells at an earlier phase than does sFasL. ${ }^{27}$

In most cell lines we have found that, as expected, in parallel to cFLIP expression reduction, activation of caspase 3, 8, and 9 appeared. This was not the case with Raji B cell line that had very high levels of activated caspase 8 at baseline. Caspase 8 and FLIP were shown to compete on binding to the death complex, FADD. ${ }^{37-40}$ Activation of caspase 8 is dependent on this binding, and leads to caspase 3 activation. ${ }^{41}$ As for caspase 9 activation, this is thought to be mediated by activated caspase 8 as well: activated caspase 8 activate Bid, and sequentially cytochrom $c$ and caspase 9 are activated. ${ }^{42-45}$ Activation of caspase 9, again, leads to caspase 3 activation and effective apoptosis. There are contradictory data concerning the role of the different splice variants of cFLIP: cFLIP short (cFLIPs) and cFLIP long (cFLIP ${ }_{L}$ ). The importance of cFLIPs as anti-apoptotic protein and inhibitor (probably competitive) of caspase 8 activation has been established. ${ }^{46,47} \mathrm{CFLIP}$ role in the system appears to be more complicated, with data indicating that very high levels of expression lead to apoptosis induction, but moderate elevation of expression results in the opposite, eg, inhibition of Fas mediated apoptosis in vitro $37,38,48,49$ and in vivo. ${ }^{50,51}$ However, data are clearer in the case of $C F L I P_{L}$ under-expression. Selective silencing of $C F L I P_{L}$ mRNA was shown to augment caspase 8 recruitment, activation, processing, and release from the death complex $^{52}$ and therefore leads to enhanced apoptosis.

The ability of CTLA-4.FasL and CD40.FasL to abolish CFLIPs and CFLIP that this can account, at least in part, for the high potency of these protein as apoptosis inducers in cells that express binding molecules to both protein's ends. Abrogating cFLIP effect in B and T cell, might affect cells survival not only by enabling more efficient activation of caspase
8 and hence more apoptosis, but also through the effect of cFLIP on NF- $\kappa$ B. In both B and T cells (and dendritic cells also), activated in the presence of FasL, activation of NF- $\kappa \mathrm{B}$ secondary to CFLIP up-regulation was seen. ${ }^{53,54}$ Silencing of $\mathrm{CFLIP}$ in $\mathrm{T}$ and $\mathrm{B}$ cells hampers their proliferation in response to suboptimal stimulation. ${ }^{54}$ In opposite, overexpression of cFLIP caused NF- $\kappa \mathrm{B}$ activation. ${ }^{55,56}$

An interesting observation of this study is the ability of CTLA-4.FasL to reduced cFLIP expression in B cell lines Raji and JY. These findings are in agreement with earlier data indicating a back-signaling through $\mathrm{B} 7$ molecules CD80 and CD86 to the B cells. ${ }^{23}$ Signaling through CD80 caused proliferation inhibition of the $\mathrm{B}$ cell and signaling through CD86 did the opposite. Importantly, CTLA4 has higher avidity to CD80. Thus one can expect, that CTLA4 binding to CD80 will also cause inhibition of proliferation as we have found when CD80 expressing Raji cells were cultured in the presence of CTLA4-Ig. Also, proliferation inhibition seen with triggering of CD80 was accompanied by down-regulation of anti-apoptotic signals as $\mathrm{Bcl}-\mathrm{xL}^{23}$ similar to the down-regulation of cFLIP that we see when Raji cells were incubated in the presence of CTLA4-Ig.

Of note, CD40.FasL caused a rapid decrease in CFLIP expression only in CD40L expressing cells, J-CD4OL . Moreover, $\mathrm{J}-\mathrm{CD} 40 \mathrm{~L}^{+}$though being relatively resistant to soluble FasL or to CTLA-4.FasL when compared with J-CD40L ${ }^{-}$cells, were by far more sensitive to CD40.FasL than $\mathrm{J}^{-C D} 40 \mathrm{~L}^{-}$cells that do not express CD40L. These findings raise the possibility of back-signaling through CD40L to the T cell, and are in agreement with previous reports that suggested the existence of such back signaling. ${ }^{33-35,57}$

Most interestingly, it was specifically shown that direct triggering of $\mathrm{CD} 40 \mathrm{~L}$ by agonistic Abs prevented the upregulation of anti-apoptotic signals, $\mathrm{Bcl}-\mathrm{XL}$ and $\mathrm{Bcl}-2$ seen during $T$ cells activation, and resulted early apoptosis of the activation T cells. ${ }^{58}$ We were not able to show any effect of CD40-Fc on CD40L positive cells, though CD40-Fc did augment their proliferation rate.

Of note, CTLA-4.FasL was found to be a potent apoptosis inducer in Jurkat $\mathrm{T}$ cell lines, even though these cells lines do not bear B7 molecules that can bind CTLA4. These cells were highly sensitive to SFasL and anti-Fas Abs (CH11, data no shown) also, with J-CD40L ${ }^{-}$ cells being more sensitive than $\mathrm{J}^{-C D} 4 \mathrm{LL}^{+}$cells to all three agents. In opposite, J-CD40L ${ }^{-}$were much less

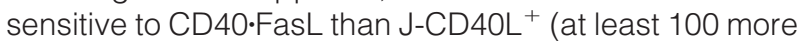
CD40L.Fas is needed to induce the same amount of apoptosis). These data suggests that the differences in potency of the different agents can result yet from other reasons. For example, it can result in from diversity in their ability to bind and activate the Fas receptor, which might be a consequence of distinct ability to form dimmers or even trimmers and/or unique tertiary forms. Of note, the present study uses his ${ }_{6}$ CTLA-4.FasL instead of nontagged CTLA-4.FasL. We have previously shown ${ }^{30}$ that these two proteins exhibit similar potency, arguing against the possibility that the hexa-histidine tag is responsible for the fusion protein's high potency in the present study. 
In summary, in this study we consolidate the concept of dual signaling by a single fusion protein that can lead to optimization of a wanted effect, in this case, apoptosis of malignant cells. The fusion proteins, with their two distinct cell binding domains, that combine pro-apoptotic signaling with abrogation of anti-apoptotic ones, have the potential to evolve into highly specific, selective, and effective agents for killing of malignant cells bearing the relevant binding molecules.

\section{References}

1. Rieux-Laucat F, Le Deist F, Hivroz C, Roberts IA, Debatin KM, Fischer A, de Villartay JP: Mutations in Fas associated with human lymphoproliferative syndrome and autoimmunity. Science 1995, 268:1347-1349

2. Martin SJ, Green DR: Protease activation during apoptosis: death by a thousand cuts? Cell 1995, 82:349-352

3. Mandruzzato S, Brasseur F, Andry G, Boon T, van der Bruggen P: A CASP-8 mutation recognized by cytolytic $T$ lymphocytes on a human head and neck carcinoma. J Exp Med 1997, 186:785-793

4. Tamura T, Ueda S, Yoshida M, Matsuzaki M, Mohri H, Okubo T: Interferon-gamma induces Ice gene expression and enhances cellular susceptibility to apoptosis in the U937 leukemia cell line. Biochem Biophys Res Commun 1996, 229:21-26

5. Clodi K, Snell V, Zhao S, Cabanillas F, Andreeff M, Younes A: Unbalanced expression of Fas and CD40 in mantle cell lymphoma. Br J Haematol 1998, 103:217-219

6. Castillo R, Mascarenhas J, Telford W, Chadburn A, Friedman SM, Schattner EJ: Proliferative response of mantle cell lymphoma cells stimulated by CD40 ligation and IL-4. Leukemia 2000, 14:292-298

7. Andersen NS, Larsen JK, Christiansen J, Pedersen LB, Christophersen NS, Geisler CH, Jurlander J: Soluble CD40 ligand induces selective proliferation of lymphoma cells in primary mantle cell lymphoma cell cultures. Blood 2000, 96:2219-2225

8. Visser HP, Tewis M, Willemze R, Kluin-Nelemans JC: Mantle cell Iymphoma proliferates upon IL-10 in the CD40 system. Leukemia 2000, 14:1483-1489

9. Planken EV, Dijkstra NH, Willemze R, Kluin-Nelemans JC: Proliferation of $\mathrm{B}$ cell malignancies in all stages of differentiation upon stimulation in the "CD40 system." Leukemia 1996, 10:488-493

10. Johnson PW, Watt SM, Betts DR, Davies D, Jordan S, Norton AJ, Lister TA: Isolated follicular lymphoma cells are resistant to apoptosis and can be grown in vitro in the CD40/stromal cell system. Blood 1993, 82:1848-1857

11. Ghia P, Boussiotis VA, Schultze JL, Cardoso AA, Dorfman DM, Gribben JG, Freedman AS, Nadler LM: Unbalanced expression of bcl-2 family proteins in follicular lymphoma: contribution of CD40 signaling in promoting survival. Blood 1998, 91:244-251

12. Greiner A, Knorr C, Qin Y, Schultz A, Marx A, Kroczek RA, MullerHermelink HK: CD40 ligand and autoantigen are involved in the pathogenesis of low-grade B-cell lymphomas of mucosa-associated Iymphoid tissue. Dev Immunol 1998, 6:187-195

13. Romano MF, Lamberti A, Tassone P, Alfinito F, Costantini S, Chiurazzi F, Defrance T, Bonelli P, Tuccillo F, Turco MC, Venuta S: Triggering of CD40 antigen inhibits fludarabine-induced apoptosis in B chronic lymphocytic leukemia cells. Blood 1998, 92:990-995

14. Kitada S, Zapata JM, Andreeff M, Reed JC: Bryostatin and CD40ligand enhance apoptosis resistance and induce expression of cell survival genes in B-cell chronic lymphocytic leukaemia. Br J Haematol 1999, 106:995-1004

15. Granziero L, Ghia P, Circosta P, Gottardi D, Strola G, Geuna M, Montagna L, Piccoli P, Chilosi M, Caligaris-Cappio F: Survivin is expressed on CD40 stimulation and interfaces proliferation and apoptosis in B-cell chronic lymphocytic leukemia. Blood 2001, 97:2777-2783

16. Lomo J, Blomhoff HK, Jacobsen SE, Krajewski S, Reed JC, Smeland EB: Interleukin-13 in combination with CD40 ligand potently inhibits apoptosis in human B lymphocytes: upregulation of Bcl-xL and $\mathrm{Mcl}-1$. Blood 1997, 89:4415-4424

17. Keller SA, Hernandez-Hopkins D, Vider J, Ponomarev V, Hyjek E,
Schattner EJ, Cesarman E: NF-kappaB is essential for the progression of KSHV- and EBV-infected lymphomas in vivo. Blood 2006, 107:3295-3302

18. Fiumara $P$, Younes $A$ : CD40 ligand (CD154) and tumour necrosis factor-related apoptosis inducing ligand (Apo-2L) in haematological malignancies. Br J Haematol 2001, 113:265-274

19. Pham LV, Tamayo AT, Yoshimura LC, Lo P, Terry N, Reid PS, Ford RJ: A CD40 Signalosome anchored in lipid rafts leads to constitutive activation of NF-kappaB and autonomous cell growth in B cell lymphomas. Immunity 2002, 16:37-50

20. Younes $A$ : The dynamics of life and death of malignant lymphocytes. Curr Opin Oncol 1999, 11:364-369

21. Storz M, Zepter K, Kamarashev J, Dummer R, Burg G, Haffner AC: Coexpression of CD40 and CD40 ligand in cutaneous T-cell lymphoma (mycosis fungoides). Cancer Res 2001, 61:452-454

22. Gribben JG, Freeman GJ, Boussiotis VA, Rennert $P$, Jellis CL, Greenfield E, Barber M, Restivo VA Jr, Ke X, Gray GS, Nadler G, Nadler LM. CTLA4 mediates antigen-specific apoptosis of human T cells. Proc Natl Acad Sci USA 1995, 92:811-815

23. Suvas S, Singh V, Sahdev S, Vohra H, Agrewala JN: Distinct role of CD80 and CD86 in the regulation of the activation of B cell and B cell lymphoma. J Biol Chem 2002, 277:7766-7775

24. Widney D, Boscardin WJ, Kasravi A, Martinez-Maza O: Expression and function of CD28 on Epstein-Barr virus-positive B cell lines and AIDS-associated non-Hodgkin's lymphoma cell lines. Tumour Biol 2003, 24:82-93

25. Huang JH, Tykocinski ML: CTLA-4-Fas ligand functions as a trans signal converter protein in bridging antigen-presenting cells and $\mathrm{T}$ cells. Int Immunol 2001, 13:529-539

26. Dranitzki-Elhalel M, Huang JH, Sasson M, Rachmilewitz J, Parnas M, Tykocinski ML: CD40.FasL inhibits human T cells: evidence for an auto-inhibitory loop-back mechanism. Int Immunol 2007, 19:355-363

27. Orbach A, Rachmilewitz J, Parnas M, Huang JH, Tykocinski ML, Dranitzki-Elhalel M: CTLA-4. FasL induces early apoptosis of activated $\mathrm{T}$ cells by interfering with anti-apoptotic signals. J Immunol 2007, 179:7287-7294

28. Azuma M, Yssel H, Phillips JH, Spits H, Lanier LL: Functional expression of B7/BB1 on activated T lymphocytes. J Exp Med 1993 177:845-850

29. Podojil JR, Kohm AP, Miller SD: CD4+ T cell expressed CD80 regulates central nervous system effector function and survival during experimental autoimmune encephalomyelitis. J Immunol 2006, 177:2948-2958

30. Elhalel MD, Huang JH, Schmidt W, Rachmilewitz J, Tykocinski ML CTLA-4. FasL induces alloantigen-specific hyporesponsiveness. J Immunol 2003, 170:5842-5850

31. Dranitzki-Elhalel M, Huang JH, Rachmilewitz J, Pappo O, Parnas M, Schmidt W, Tykocinski ML: CTLA-4.FasL inhibits allogeneic responses in vivo. Cell Immunol 2006, 239:129-135

32. Cayabyab M, Phillips JH, Lanier LL: CD40 preferentially costimulates activation of CD4+ T lymphocytes. J Immunol 1994, 152:1523-1531

33. Bennett SR, Carbone FR, Karamalis F, Flavell RA, Miller JF, Heath WR: Help for cytotoxic-T-cell responses is mediated by CD40 signalling. Nature 1998, 393:478-480

34. Brenner B, Koppenhoefer U, Grassme H, Kun J, Lang F, Gulbins E: Evidence for a novel function of the CD40 ligand as a signalling molecule in T-lymphocytes. FEBS Lett 1997, 417:301-306

35. Brenner B, Koppenhoefer U, Lepple-Wienhues A, Grassme H, Muller C, Speer CP, Lang F, Gulbins E: The CD40 ligand directly activates T-lymphocytes via tyrosine phosphorylation dependent PKC activation. Biochem Biophys Res Commun 1997, 239:11-17

36. Thome M, Schneider P, Hofmann K, Fickenscher H, Meinl E, Neipel F, Mattmann C, Burns K, Bodmer JL, Schroter M, Scaffidi C, Krammer PH, Peter ME, Tschopp J: Viral FLICE-inhibitory proteins (FLIPS) prevent apoptosis induced by death receptors. Nature 1997, 386:517-521

37. Hu S, Vincenz C, Ni J, Gentz R, Dixit VM: I-FLICE, a novel inhibitor of tumor necrosis factor receptor-1- and CD-95-induced apoptosis. J Biol Chem 1997, 272:17255-17257

38. Irmler M, Thome M, Hahne M, Schneider P, Hofmann K, Steiner V, Bodmer JL, Schroter M, Burns K, Mattmann C, Rimoldi D, French LE, Tschopp J: Inhibition of death receptor signals by cellular FLIP. Nature 1997, 388:190-195

39. Kirchhoff S, Muller WW, Krueger A, Schmitz I, Krammer PH: TCRmediated up-regulation of C-FLIP short correlates with resistance 
toward CD95-mediated apoptosis by blocking death-inducing signaling complex activity. J Immunol 2000, 165:6293-6300

40. Schmitz I, Weyd H, Krueger A, Baumann S, Fas SC, Krammer PH, Kirchhoff S: Resistance of short term activated T cells to CD95mediated apoptosis correlates with de novo protein synthesis of C-FLIPshort. J Immunol 2004, 172:2194-2200

41. Cohen GM: Caspases: the executioners of apoptosis. Biochem $J$ 1997, 326(Pt 1):1-16

42. Luo X, Budihardjo I, Zou H, Slaughter C, Wang X: Bid, a Bcl2 interacting protein, mediates cytochrome $\mathrm{c}$ release from mitochondria in response to activation of cell surface death receptors. Cell 1998, 94:481-490

43. Li H, Zhu H, Xu CJ, Yuan J: Cleavage of BID by caspase 8 mediates the mitochondrial damage in the Fas pathway of apoptosis. Cell 1998, 94:491-501

44. Ashkenazi A, Dixit VM: Death receptors: signaling and modulation. Science 1998, 281:1305-1308

45. Kruidering M, Evan Gl: Caspase-8 in apoptosis: the beginning of "the end"? IUBMB Life 2000, 50:85-90

46. Krueger A, Baumann S, Krammer PH, Kirchhoff S: FLICE-inhibitory proteins: regulators of death receptor-mediated apoptosis. Mol Cell Biol 2001, 21:8247-8254

47. Thome M, Tschopp J: Regulation of Iymphocyte proliferation and death by FLIP. Nat Rev Immunol 2001, 1:50-58

48. Scaffidi C, Schmitz I, Krammer PH, Peter ME: The role of C-FLIP in modulation of CD95-induced apoptosis. J Biol Chem 1999, 274: $1541-1548$

49. Krueger A, Schmitz I, Baumann S, Krammer PH, Kirchhoff S: Cellular FLICE-inhibitory protein splice variants inhibit different steps of caspase-8 activation at the CD95 death-inducing signaling complex. J Biol Chem 2001, 276:20633-20640

50. Medema JP, de Jong J, van Hall T, Melief CJ, Offringa R: Immune escape of tumors in vivo by expression of cellular FLICE-inhibitory protein. J Exp Med 1999, 190:1033-1038

51. Djerbi M, Screpanti V, Catrina Al, Bogen B, Biberfeld P, Grandien A The inhibitor of death receptor signaling: FLICE-inhibitory protein defines a new class of tumor progression factors. J Exp Med 1999, 190:1025-1032

52. Sharp DA, Lawrence DA, Ashkenazi A: Selective knockdown of the long variant of cellular FLICE inhibitory protein augments death receptor-mediated caspase-8 activation and apoptosis. J Biol Chem 2005, 280:19401-19409

53. Kataoka T, Budd RC, Holler N, Thome M, Martinon F, Irmler M, Burns K, Hahne M, Kennedy N, Kovacsovics M, Tschopp J: The caspase-8 inhibitor FLIP promotes activation of NF-kappaB and Erk signaling pathways. Curr Biol 2000, 10:640-648

54. Golks A, Brenner D, Krammer PH, Lavrik IN: The c-FLIP-NH2 terminus (p22-FLIP) induces NF-kappaB activation. J Exp Med 2006, 203:1295-1305

55. Hu WH, Johnson H, Shu HB: Activation of NF-kappaB by FADD, Casper, and caspase-8. J Biol Chem 2000, 275:10838-10844

56. Chaudhary PM, Eby MT, Jasmin A, Kumar A, Liu L, Hood L: Activation of the NF-kappaB pathway by caspase 8 and its homologs. Oncogene 2000, 19:4451-4460

57. Blair PJ, Riley JL, Harlan DM, Abe R, Tadaki DK, Hoffmann SC, White $L$, Francomano $T$, Perfetto SJ, Kirk AD, June $C H$ : CD40 ligand (CD154) triggers a short-term CD4(+) T cell activation response that results in secretion of immunomodulatory cytokines and apoptosis. J Exp Med 2000, 191:651-660

58. Travert M, Ame-Thomas P, Pangault C, Morizot A, Micheau O, Semana G, Lamy T, Fest T, Tarte K, Guillaudeux T: CD40 ligand protects from TRAIL-induced apoptosis in follicular lymphomas through NF-kappaB activation and up-regulation of C-FLIP and BclxL. J Immunol 2008, 181:1001-1011 